\title{
The biomechanical characteristics of high-performance endurance running
}

\section{Abstract}

The biomechanical profile of high-level endurance runners may represent a useful model that could be used for developing training programmes designed to improve running style. This study therefore sought to compare the biomechanical characteristics of high-performance and recreational runners. Kinematic and kinetic measurements were taken during overground running from a cohort of 14 highperformance ( 8 male) and 14 recreational ( 8 male) runners, at four speeds ranging from 3.3 to $5.6 \mathrm{~ms}^{-1}$. Two-way ANOVA analysis was then used to explore group and speed effects and principal component analysis to explore the interdependence of the tested variables. The data showed the high-performance runners to have a gait style characterised by an increased vertical velocity of the centre of mass and a flight time that was $11 \%$ longer than the recreational group. The high-performance group were also observed to adopt a forefoot strike pattern, to contact the ground with their foot closer to their body and to have a larger ankle moment. Importantly, although observed group differences were mostly independent of speed, the tested variables showed a high degree of interdependence suggesting an underlying unitary phenomenon. This is the first study to compare high-performance and recreational runners across a full range of kinematic and kinetic variables. The results suggest that high-performance runners maintain stride length with a prolonged aerial phase, rather than by landing with a more extended knee. These findings motivate future intervention studies that should investigate whether recreational runners could benefit from instruction to decrease shank inclination at foot contact. 
Keywords: Running biomechanics; High-performance running; elite running, Running speed; Gait analysis; centre of mass 


\section{Introduction}

Participation in running has grown rapidly over recent years, with recent estimates suggesting that over $15 \%$ of the UK adult population now participate in runningrelated sport (Active Lives Survey, 2015). With this growth in participation has been an increase in the number training programmes designed to improve individual running performance (Dreyer \& Dreyer, 2009; Romanov 2004). However, many of these programmes are based on contemporary opinion rather than robust scientific evidence documenting the links between running technique and performance. Moreover, although there has been some previous research seeking to identify the biomechanical determinants of running economy (Barnes \& Kilding, 2015), there are only a small number of studies which characterise the biomechanical profile of highlevel endurance running (Clermont, Osis, Phinyomark, \& Ferber, 2017; Padulo, Annino, Migliaccio, D'Ottavio, \& Tihanyi, 2012). We suggest that these characteristics could be used to inform intervention studies that could ultimately inform the development of programmes aimed at improving running technique.

One approach to characterising the running technique of high-level performers is to compare runners of different performance abilities (Larson et al., 2011) during a competitive race. Using this approach, previous workers have observed decreased contact times (Hayes \& Caplan, 2012) and alterations in foot contact pattern (Hasegawa, Yamauchi, \& Kraemew, 2007) to be linked to finishing time. However, under controlled conditions, running speed is known to have a strong and predictable effect on a spatiotemporal parameters (Padulo et al., 2012), foot strike patterns 
(Forrester \& Townend, 2015) as well as lower extremity kinematic and kinetic variables (Petersen, Nielsen, Rasmussen, \& Sorensen, 2014; Schache et al., 2011). This speed dependence means that it is difficult to interpret the findings of fieldbased studies that suggest that a shorter contact time and/or a forefoot strike are intrinsic characteristics of high-level endurance running. In order to provide further clarification on these issues, biomechanical comparison needs to be performed at carefully controlled speeds.

Two recent studies have attempted to identify biomechanical characteristics of highperformance endurance runners under controlled conditions. In the first study, Padulo et al. (2012) defined a group, which they referred to as "elite" endurance runners, based on an average personal best $(\mathrm{PB})$ marathon speed of $5.1 \mathrm{~ms}^{-1}(2 \mathrm{~h}: 21$ marathon time). During treadmill running, the elite group were observed to exhibit longer flight times and to run with lower stride frequency than an "amateur" group. In a more recent study, Clermont et al. (2017) sought to differentiate between "competitive" and "recreational" runners. The competitive runners had an average PB 10Km speeds of $4.8 \mathrm{~ms}^{-1}$ (35 min 10Km time) and were observed to have more knee and hip flexion at the end of the flight phase and during early stance. However, it is important to acknowledge that both these studies reported data collected during treadmill running which is known to affect preferred stride frequency (Franz et al., 2008; Schache et al., 2001) when compared to overground running. Further research is therefore required to fully characterise the biomechanical profile of highperformance endurance running. 
Increases in stride length, at a given running speed, can be achieved by spending more time in the air or by landing with a more extended hip or knee, often referred to as overstride. During the flight phase of running, the centre of mass $(\mathrm{CoM})$ follows a ballistic trajectory; therefore, increases in stride length which result from a prolonged aerial phase, are likely to be the result of an increased vertical impulse during the stance phase. Given the previous observation that high-performance running is characterised by an increased flight time (Padulo et al., 2012), and a more flexed knee prior to foot contact (Clermont et al., 2017), it is likely that high-performance runners exploit this prolonged aerial phase to land with the foot closer to the body without adversely affecting stride length. Interestingly, some running programmes (Romanov \& Brungardt, 2014) specifically cue runners to land with a relatively vertical shank in order to minimise overstride.

Without compensatory changes in ankle dorsiflexion, a more vertical tibia at landing will tend to lead to a midfoot or forefoot strike. It is also possible that a pattern of reduced overstride could affect biomechanical characteristics later in stance. Specifically, a forefoot strike pattern, combined with a more posterior foot position at foot contact, may lead to a relative anterior shift in the centre of pressure $(\mathrm{CoP})$ during early stance (Becker, Pisciotta, James, Osternig, \& Chou, 2014). When combined with an increase in the vertical ground reaction force (increased impulse), this alteration in the CoP will increase the ankle plantarflexor moment.

There has been minimal previous research investigating the biomechanical characteristics of high-performance runners during controlled, overground running. Furthermore, it is not clear to what extent the previous observations of increased flight times in high-performance runners could be associated with other biomechanical characteristics. We sought to test the hypothesis that high- 
performance overground running is characterised by an increased flight time, a more flexed knee at contact, a forefoot strike pattern and a higher ankle joint moment. We also sought to understand the potential interdependence between these biomechanical characteristics.

\section{Methods}

A cohort of 14 high-performance ( 8 male) and 14 recreational endurance runners ( 8 male), recruited through local running clubs and via community advert, participated in the study. The size of this sample was chosen based on data reported by Padulo et al. (2012) in which there was a difference in flight time of 1.5 SD between recreational and high-performance runners. Based on these data, an a priori sample size calculation was performed using the $\mathrm{g}^{*}$ power software. This showed that a sample of $\mathrm{n}=11$ in each group would be required to detected a difference of $1.5 \mathrm{SD}$ with a power of 0.9 and an $\alpha=0.05$. In the recreational group, participants were required to have a personal best $10 \mathrm{~km}$ time no better than 38 minutes (males) and 42 minutes (females) over the preceding 12 months. In contrast, the high-performance runners were required to have achieved a time of less than 32 minutes (males) or less than 36 minutes (females). All participants were required to have at least 5 years of running experience and had to be free of any musculoskeletal pain during the 6 months prior to testing. Further details of the group characteristics are provided in Table 1. Ethical approval for this study was obtained before the study began from the University of Salford Ethical Review panel. All participants signed an informed consent form approved by the University review panel in accordance with University policy.

TABLE 1 HERE 
Each participant completed a 10 minute initial warm up and then ran along a $32 \mathrm{~m}$ track at four different running speeds in their own running shoes. The speeds chosen for the study were 3.3, 3.9, 4.8 and $5.6 \mathrm{~ms}^{-1}$ which were monitored using optical timing gates to ensure participants ran within $2.5 \%$ of each target speed. At each speed, kinematic data were collected from skin-mounted reflective markers using a 12-camera Qualisys pro-reflex system $(240 \mathrm{~Hz})$. In addition, force data were collected using three AMTI force platforms $(1200 \mathrm{~Hz})$ embedded within the track. Participant were instructed to look straight ahead whilst running and not to target the force platforms. The layout of the force platform was such that participants contacted the first platform with their right foot and either the second or the third platform with the left foot. Participants practiced at each condition for 5 minutes and, once they were able to run consistently, a minimum of 5 trials were collected at each speed.

Kinematic data were collected from reflective markers placed on the thorax, lumbar spine, pelvis and also the thigh, shank and foot of each lower limb. The specific details of the kinematic protocol used to define and track each of the nine segments in described in detail in two previous publications (Mason, Preece, Bramah, \& Herrington, 2016; Preece, Mason, \& Bramah, 2016). Kinematic and kinetic data were analysed using Visual 3D (C-Motion). Raw marker data were low pass filtered at $10 \mathrm{~Hz}$ and segment masses for each of the nine segments calculated using data from Dempster (1955). For these calculations the pelvis, lumbar spine and thoracic segments were modelled as elliptical cylinders and each of the lower extremity segments assumed to be frustra of a cone, see Preece et al. (2016) for further details. In order to calculate segmental kinematics, and corresponding joint moments, a global optimisation algorithm was used in which each of the nine segments could rotate (3 
rotational degrees of freedom) but not translate relative to adjacent segments, see (Mason et al., 2016; Preece et al., 2016) for further details and reproducibility measurements. The final CoM of the full model was calculated as a weighted average of all nine segments. This was then adjusted, in the anterior-posterior (AP) and vertical directions, using the correction factors suggested by Gill et al. (2017) to account for the effect of the arms and the head.

The timing of foot strike and toe off for each foot was obtained from the force plate data and kinematic data, using an automated event detection algorithm (Stanhope, Kepple, McGuire, \& Roman, 1990). Gait data were then time normalised to a complete gait cycle (right foot strike to right foot strike) and ensemble average curves created for each participant at each of the four separate different speeds. Specific outcomes were then derived from either the ensemble average data or the non-normalised data. For outcomes derived from non-normalised data, an average across all trials was calculated for each subject at each speed. We derived a set of nine primary variables that captured different aspects of our proposed hypothesis around high-performance running and which were likely to be interdependent. In addition, we derived a further set of eight secondary variables to facilitate comparison with other research and to provide a more complete picture of the differences between the groups.

Our primary variables included vertical impulse, vertical velocity of the CoM at toe off and flight time (between right toe off and left foot contact). We also included shank angle (relative to the laboratory) at initial contact, knee flexion angle at initial contact, foot strike index and AP distance between the CoM and the ankle joint centre (AJC- 
CoM) at initial contact. The foot strike index was defined as the position of the centre of pressure at the instant of foot contact, along the longitudinal axis of the foot, and was expressed as a fraction of foot length (Altman \& Davis, 2012). The final two primary variables were the position of the $\mathrm{CoP}$ relative to the ankle centre at midstance (taken as the point when the AP ground reaction force changed from negative to positive) and the peak ankle moment.

Our set of eight secondary variables included peak vertical ground reaction force, contact time, stride frequency, stride length, ankle plantarflexion and hip flexion angle at contact and peak knee/hip moments. In order to compare data between different participants, all biomechanical variables (both primary and secondary) were made dimensionless (Hof, 1996). Specifically, forces were normalised by body weight $\left(m_{0} g\right)$, distances normalised by leg length $\left(l_{0}\right)$ and time normalised by dividing by $\sqrt{ }\left(l_{0} / g\right)$. Note that leg length $\left(l_{0}\right)$ was calculated as the distance from the greater trochanter to the floor during the static trial. In addition, stride frequency was made dimensionless by dividing by $\sqrt{ }\left(g / l_{0}\right)$, velocity normalised by dividing by $\sqrt{ }\left(g l_{0}\right)$ and moments normalised by dividing by $\left(m_{0} g l_{0}\right)$.

We used a two-way repeated-measures ANOVA analysis to test for group differences (high-performance vs recreational) and to understand if there were any group by speed interactions. Such interactions indicate that differences between the groups were speed dependent. A separate ANOVA test was performed for each primary and each secondary variable. Statistical significance was determined by using the BonferroniHolm method to adjust the target critical alpha of 0.05. Specifically, this approach was 
used to adjust for nine separate primary variables and then again for eight separate secondary variables. In addition, an effect size (Cohen's d) was calculated from the mean (across speeds) data, for each separate outcome, to provide an indication of the magnitude of the differences between the two groups. Following the ANOVA analysis, we used principal component analysis (PCA) to determine the level of interdependence between our nine primary outcome variables. This PCA analysis was performed separately for each running speed and included all $n=28$ participants.

\section{Results}

Eight out of the nine primary variables were observed to be significantly different between the high-performance and recreational runners with large effect sizes, ranging from 0.94 to 2.23 (Table 2). Interestingly, although all variables showed a strong speed dependence, there were no group by speed interactions (Table 2) demonstrating that the differences between the groups were largely independent of speed. In line with our hypothesis, the high-performance runners exhibited a higher vertical impulse (Figure 1a, Table 2) and higher vertical velocity of the CoM at toe off (Table 2) which led to an $11 \%$ longer flight time. The high-performance runners were also observed to contact the ground with the shank on average (across the four speeds) $4.4^{\circ}$ closer to the vertical than the recreational runners (Table 2).

Interestingly, knee flexion angle was almost identical for the two groups between 75$90 \%$ of the gait cycle (Figure $1 \mathrm{~b}$ ). However, during the period $90-100 \%$ of the gait cycle, the high-performance runners appeared to begin flexing their knee earlier and this lead to $5^{\circ}$ more knee flexion at foot contact (Table 2). Nevertheless, although the effect size was large (Table 2), this difference failed to reach statistical significance. 


\section{TABLE 2 HERE}

The average (across the four speeds) foot strike index was significantly different between the groups (Table 2), indicating a predominantly forefoot pattern in the high-performance group and a rearfoot pattern in the recreational group. When a threshold of 0.33 was used group participants by foot strike pattern, only 5, 4, 2 and 0 of the high-performance runners were observed to adopt a rearfoot pattern at the four speeds respectively. In contrast, 11, 11, 10 and 8 of the recreational runners were classified as rearfoot strikers at the corresponding four speeds. The highperformance group were observed to strike the ground with the foot, on average (across the four speeds), 17\% closer to the CoM than the recreational runners (Table 3). This foot position, combined with a forefoot strike pattern, lead to a more anterior CoP position in the high-performance group at midstance (Figure 1c, Table 2) and an increased ankle plantarflexor moment (Figure 1d, Table 2).

\section{FIGURE 1 HERE}

Of the secondary variables, only peak vGRF was observed to be significantly different between the two groups (Table 3). Interestingly, there were no differences in peak knee or hip moments nor was there any difference in hip flexion or ankle plantarflexion at initial contact (Table 3), indicating that the difference in shank angle (Table 2) resulted from a more flexed knee at contact. The PCA analysis showed that a single component could be used to account for $89 \%, 91 \%, 93 \%$ and $92 \%$ of the variance in the nine primary variables across the four different speeds respectively. However, with two principal components it was possible to account for almost all (>99\%) of the variance in the nine variables at each separate speed. 


\section{TABLE 3 HERE}

\section{Discussion}

This study sought to quantify the biomechanical differences between a group of recreational and a group of high-performing endurance runners. In order to ensure that this comparison was not influenced by anthropometric variation, all outcome variables were made dimensionless. The data supported our hypothesis, showing high-performance running to be characterised by an increased vertical impulse, an increased velocity of the CoM at toe off and a longer flight time. The data also supported idea that the high-performance runners adopt a predominately forefoot strike pattern, contact the ground with their foot closer to their CoM and generate higher peak ankle moments. These data support the idea that high-performance endurance runners maintain stride length by generating a higher vertical impulse, which leads to more vertical motion of the CoM, rather than by landing with a more extended knee.

None of the biomechanical variables tested showed a group by speed interaction (Tables $2 \& 3$ ), demonstrating that the characteristics of high-performance running were not speed dependent. This is important because our highest speed of $5.6 \mathrm{~ms}^{-1}$ is not representative of a typical recreational running and our lowest speed of $3.3 \mathrm{~ms}^{-1}$ is not representative of high-performance running. Furthermore, principal component analysis showed a clear interdependence between the nine primary variables, indicating that these measurements were capturing different aspects of a single underlying phenomenon. Given this interdependence, it is possible that cueing a 
runner to change one aspect of their running style, such as shank inclination at initial contact, may produce corresponding changes in the other primary variables (Table 2).

It is interesting to compare the findings of this present study to previous research that has sought to identify the biomechanical characteristics of high-performance treadmill running. Our data appear consistent with Clermont et al. (2017) who reported increased knee flexion at the end of swing phase, immediately prior to initial contact (Figure 1b). Our data also support the idea that high-performance runners tend to adopt a forefoot strike pattern (Hasegawa et al., 2007), contact the ground with the shank in a more vertical position (Folland, Allen, Black, Handsaker, \& Forrester, 2017) and exhibit a prolonged aerial phase (Padulo et al., 2012). In their study, Folland et al. (2017) observed a link between less vertical oscillation of the pelvis and better race performance. However, this relationship was only apparent across stance phase and did not exist when the entire gait cycle was analysed. In order to prolong the aerial phase of running, it is necessary to increase the vertical velocity of the CoM at toe off. However, this will not necessarily be associated with increased vertical motion of the CoM during the stance phase. It is therefore possible that high-performance running is associated with less vertical motion of the pelvis during stance but more vertical motion of the pelvis during flight phase.

The high-performance runners in our study exhibited a predominately forefoot strike pattern. It is therefore important to consider whether the observed differences could be the result of a different strike pattern rather than intrinsic characteristics of high- 
performance running. Similar to the differences observed in our study, previous research comparing rearfoot and forefoot runners have observed forefoot runners to contact the ground with a more flexed knee (Ahn, Brayton, Bhatia, \& Martin, 2014) and with the foot closer to the CoM (Kulmala, Avela, Pasanen, \& Parkkari, 2013). However, contrasting findings have been reported for peak ankle moment, with some reporting no differences (Stearne, Alderson, Green, Donnelly, \& Rubenson, 2014) and others reporting higher moments to be associated with a forefoot strike pattern (Kulmala et al., 2013). Importantly, both overground (Kulmala et al., 2013) and treadmill (Ahn et al., 2014) studies have shown forefoot strikers to contact the ground with the ankle in at least $15^{\circ}$ more plantarflexion than rearfoot strikers. This difference in plantarflexion angle at initial contact was not observed in our study as the difference in foot position (foot strike index) in the high-performance group was offset by a more vertical shank. Previous research has also demonstrated that a forefoot strike pattern is not associated with a higher peak vGRF (Kulmala et al., 2013; Valenzuela, Lynn, Mikelson, Noffal, \& Judelson, 2015) nor is it associated with a longer flight time (Stearne et al., 2014). Given these contrasting findings, it would appear that the differences observed in this study are a characteristic of high-performance endurance running and cannot simply be attributed to a forefoot strike pattern.

In the high-performance runners, the ankle plantarflexor moment was larger, peaked earlier and appeared to increase more rapidly during early stance when compared to the recreational runners (Figure 1d). During the first $5 \%$ of the gait cycle the evolution of the vGRF was observed to be very similar between the two groups (Figure 1a). Therefore, the more rapid increase in the plantarflexor moment most likely resulted from a more anteriorly positioned CoP (Figure 1c). Previous 
modelling studies have demonstrated that the ankle plantarflexor muscles provide the greatest contribution to vertical acceleration of the CoM during the late stance phase of running (Hamner \& Delp, 2013; Hamner, Seth, \& Delp, 2010). It has also been suggested that the elastic energy stored within a tendon varies with the square of the joint moment (Scholz, Bobbert, van Soest, Clark, \& van Heerden, 2008). It is therefore possible that high-performance runners rapidly increase the ankle moment during early stance in order to increase the storage of elastic energy in the Achilles tendon. This energy is subsequently returned during the second half of stance, maximising vertical velocity of the CoM at toe-off and therefore increasing the length of the aerial phase. Interestingly, this increased flight time did not lead to an increase in stride length as possible gains were offset with a landing pattern in which the shank was more vertical and the foot closer to the CoM. Nevertheless, as explained above, this landing strategy may be necessary to rapidly increase the ankle moments and therefore maximise elastic energy storage in the Achilles tendon.

It is useful to speculate on the underlying reasons for the observed differences between the high-performance and recreational runners. A recent study demonstrated no relationship between joint kinematics and running experience (Agresta, Peacock, Housner, Zernicke, \& Zendler, 2018). Therefore, we suggest the characteristics of high-performance runners either are the result of a subconscious adaptation to increased weekly distance (training load) or are intrinsic characteristics that enable these runners to perform at a high level. Whatever the mechanism, we suggest that our data could form the starting point for future intervention studies aimed at improving running performance. We observed a similar stride frequency between the high-performance and recreational runners and this might not support the practice of 
altering stride frequency. However, it has been shown that cueing runners to increase stride frequency leads to reduced overstride, i.e. a foot contact position closer to the centre of mass (Heiderscheit, Chumanov, Michalski, Wille, \& Ryan, 2011; Lieberman, Warrener, Wang, \& Castillo, 2015). Nevertheless, this previous research does not provide insight into the effect of simply cueing runners to reduce overstride Given the interdependence of the biomechanical variables reported in this study, we suggest that reducing overstride may increase ankle moment which may, in turn, lead to a longer aerial phase. Therefore, further research is required to understand the effect of independently manipulating overstride during both overground and treadmill running.

There are a number of limitations to this study that should be acknowledged. Firstly, because we chose to investigate overground running rather than treadmill running, it was not possible to precisely control running speed. This decision was motivated by previous research which has shown treadmill running to affect stride frequency (Franz et al., 2008; Schache et al., 2001). However, with our protocol we were able to ensure that each trial was within $2.5 \%$ of the target speed and, during data analysis we confirmed that the mean speeds for each group were almost identical. Another limitation of this study was the use of a nine-segmental model to estimate CoM. However, in a recent publication (Gill et al., 2017) we have shown, that provided an appropriate correction factor is used, this approach provides an accurate estimate of CoM motions in the anterior-posterior and vertical directions. A final limitation is that, in order to characterise the biomechanical differences between the two groups, a relatively large number of variables were studied, and this may increase the likelihood of type 1 error. However, we used a Bonferroni-Holm correction to minimise this risk 
and also demonstrated strong interdependence between our nine primary variables. This interdependence suggests that these variables measure different aspects of the same underlying phenomenon. However, we do acknowledge that the small sample size may not fully represent the entire population of high-performing runners and that the specific movement patterns identified in this study may have been specific to our sample.

\section{Conclusion}

This is the first study to compare high-performance and recreational runners across a full range of kinematic and kinetic variables. Our analysis identified characteristics of high-performance running which, although independent of running speed, appear to be interdependent. Specifically, running style in our cohort of high-performance runners was characterised by longer flight times that facilitate a landing pattern in which the foot is positioned closer to the body. However, we acknowledge that further research is required to confirm whether our sample is fully representative of high-performance running. Nevertheless, our data motivate future prospective studies that could aim to understand how manipulating shank inclination and/or foot position at initial contact could affect running performance.

\section{References:}

Active Lives survey (2015). London: Sport Available from:

https://www.sportengland.org/media/11498/active-lives-survey-yr-1-report.pdf 
Agresta, C. E., Peacock, J., Housner, J., Zernicke, R. F., \& Zendler, J. D. (2018). Experience does not influence injury-related joint kinematics and kinetics in distance runners. Gait Posture, 61, 13-18. doi: 10.1016/j.gaitpost.2017.12.020

Ahn, A. N., Brayton, C., Bhatia, T., \& Martin, P. (2014). Muscle activity and kinematics of forefoot and rearfoot strike runners. Journal of Sport and Health Science, 3(2), 102112. doi: 10.1016/j.jshs.2014.03.007

Altman, A. R., \& Davis, I. S. (2012). A kinematic method for footstrike pattern detection in barefoot and shod runners. Gait \& Posture, 35(2), 298-300. doi: 10.1016/j.gaitpost.2011.09.104

Barnes, K. R., \& Kilding, A. E. (2015). Running economy: measurement, norms, and determining factors. Sports Med Open, 1(1), 8. doi: 10.1186/s40798-015-0007-y

Becker, J., Pisciotta, E., James, S., Osternig, L. R., \& Chou, L.-S. (2014). Center of pressure trajectory differences between shod and barefoot running. Gait \& Posture, 40(4), 504-509. doi: 10.1016/j.gaitpost.2014.06.007

Clermont, C. A., Osis, S. T., Phinyomark, A., \& Ferber, R. (2017). Kinematic Gait Patterns in Competitive and Recreational Runners. J Appl Biomech, 1-26. doi: 10.1123/jab.2016-0218

Dempster, W. T. (1955). Space requirements of the seated operator (Rep. No. Technical report WADC-TR-55-159). Ohio: Wright-Patterson Air Force Base.

Dreyer, D., \& Dreyer, K. (2009). Chi Running: A Revolutionary Approach to Effortless, InjuryFree Running: Touchstone.

Folland, J. P., Allen, S. J., Black, M. I., Handsaker, J. C., \& Forrester, S. E. (2017). Running Technique is an Important Component of Running Economy and Performance. Med Sci Sports Exerc, 49(7), 1412-1423. doi: 10.1249/mss.0000000000001245

Forrester, S. E., \& Townend, J. (2015). The effect of running velocity on footstrike angle - A curve-clustering approach. Gait \& Posture, 41(1), 26-32. doi: 10.1016/j.gaitpost.2014.08.004

Franz, J. R., Dicharry, J., Riley, P. O., Jackson, K., Wilder, R. P., \& Kerrigan, D. C. (2008). The influence of arch supports on knee torques relevant to knee osteoarthritis.

Medicine and Science in Sports and Exercise, 40(5), 913-917. doi: 10.1249/MSS.0b013e3181659c81

Gill, N., Preece, S. J., Young, S., \& Bramah, C. (2017). Are the arms and head required to accurately estimate centre of mass motion during running? Gait Posture, 51, 281283. doi: 10.1016/j.gaitpost.2016.11.001

Hamner, S. R., \& Delp, S. L. (2013). Muscle contributions to fore-aft and vertical body mass center accelerations over a range of running speeds. Journal of Biomechanics, 46(4), 780-787. doi: 10.1016/j.jbiomech.2012.11.024

Hamner, S. R., Seth, A., \& Delp, S. L. (2010). Muscle contributions to propulsion and support during running. Journal of Biomechanics, 43(14), 2709-2716. doi: 10.1016/j.jbiomech.2010.06.025

Hasegawa, H., Yamauchi, T., \& Kraemew, W. J. (2007). Foot strike patterns of runners at the 15-km point during an elite-level half marathon. Journal of Strength and Conditioning Research, 21(3), 888-893. doi: 10.1519/r-22096.1

Hayes, P., \& Caplan, N. (2012). Foot strike patterns and ground contact times during highcalibre middle-distance races. J Sports Sci, 30(12), 1275-1283. doi: 10.1080/02640414.2012.707326

Heiderscheit, B. C., Chumanov, E. S., Michalski, M. P., Wille, C. M., \& Ryan, M. B. (2011). Effects of Step Rate Manipulation on Joint Mechanics during Running. Medicine and Science in Sports and Exercise, 43(2), 296-302. doi:

10.1249/MSS.0b013e3181ebedf4 
Hof, A. L. (1996). Scaling gait data to body size. Gait \& Posture, 4(3), 222-223. doi: 10.1016/0966-6362(95)01057-2

Kulmala, J.-P., Avela, J., Pasanen, K., \& Parkkari, J. (2013). Forefoot Strikers Exhibit Lower Running-Induced Knee Loading than Rearfoot Strikers. Medicine and Science in Sports and Exercise, 45(12), 2306-2313. doi: 10.1249/MSS.0b013e31829efcf7

Larson, P., Higgins, E., Kaminski, J., Decker, T., Preble, J., Lyons, D., \& Normile, A. (2011). Foot strike patterns of recreational and sub-elite runners in a long-distance road race. Journal of Sports Sciences, 29(15), 1665-1673. doi: 10.1080/02640414.2011.610347

Lieberman, D. E., Warrener, A. G., Wang, J., \& Castillo, E. R. (2015). Effects of stride frequency and foot position at landing on braking force, hip torque, impact peak force and the metabolic cost of running in humans. Journal of Experimental Biology, 218(21), 3406-3414. doi: 10.1242/jeb.125500

Mason, D. L., Preece, S. J., Bramah, C. A., \& Herrington, L. C. (2016). Reproducibility of kinematic measures of the thoracic spine, lumbar spine and pelvis during fast running. Gait \& Posture, 43, 96-100. doi: 10.1016/j.gaitpost.2013.11.007

Padulo, J., Annino, G., Migliaccio, G. M., D'Ottavio, S., \& Tihanyi, J. (2012). Kinematics of running at different slopes and speeds. Journal of Strength and Conditioning Research, 26(5), 1331-1339. doi: 10.1519/JSC.0b013e318231aafa

Petersen, J., Nielsen, R. O., Rasmussen, S., \& Sorensen, H. (2014). Comparisons of increases in knee and ankle joint moments following an increase in running speed from 8 to 12 to 16 km/h. Clinical Biomechanics, 29(9), 959-964. doi: 10.1016/j.clinbiomech.2014.09.003

Preece, S. J., Mason, D., \& Bramah, C. (2016). The coordinated movement of the spine and pelvis during running. Human movement science, 45, 110-118. doi: 10.1016/j.humov.2015.11.014

Romanov, N. (2004). Pose Method of Running: Pose Tech Press.

Romanov, N., \& Brungardt, K. (2014). The Running Revolution: How to Run Faster, Farther, and Injury-Free--for Life. New York: Penguin books.

Schache, A. G., Blanch, P. D., Dorn, T. W., Brown, N. A., Rosemond, D., \& Pandy, M. G. (2011). Effect of running speed on lower limb joint kinetics. Medicine and science in sports and exercise, 43(7), 1260-1271. doi: 10.1249/MSS.0b013e3182084929

Schache, A. G., Blanch, P. D., Rath, D. A., Wrigley, T. V., Starr, R., \& Bennell, K. L. (2001). A comparison of overground and treadmill running for measuring the threedimensional kinematics of the lumbo-pelvic-hip complex. Clinical Biomechanics, 16(8), 667-680. doi: 10.1016/s0268-0033(01)00061-4

Scholz, M. N., Bobbert, M. F., van Soest, A. J., Clark, J. R., \& van Heerden, J. (2008). Running biomechanics: shorter heels, better economy. Journal of Experimental Biology, 211(Pt 20), 3266-3271. doi: 10.1242/jeb.018812

Stanhope, S. J., Kepple, T. M., McGuire, D. A., \& Roman, N. L. (1990). Kinematic-based technique for event time determination during gait. Medical \& biological engineering \& computing, 28(4), 355-360

Stearne, S. M., Alderson, J. A., Green, B. A., Donnelly, C. J., \& Rubenson, J. (2014). Joint Kinetics in Rearfoot versus Forefoot Running: Implications of Switching Technique. Medicine and Science in Sports and Exercise, 46(8), 1578-1587. doi: 10.1249/mss.0000000000000254

Valenzuela, K. A., Lynn, S. K., Mikelson, L. R., Noffal, G. J., \& Judelson, D. A. (2015). Effect of Acute Alterations in Foot Strike Patterns during Running on Sagittal Plane Lower Limb Kinematics and Kinetics. J Sports Sci Med, 14(1), 225-232 
Figure 1
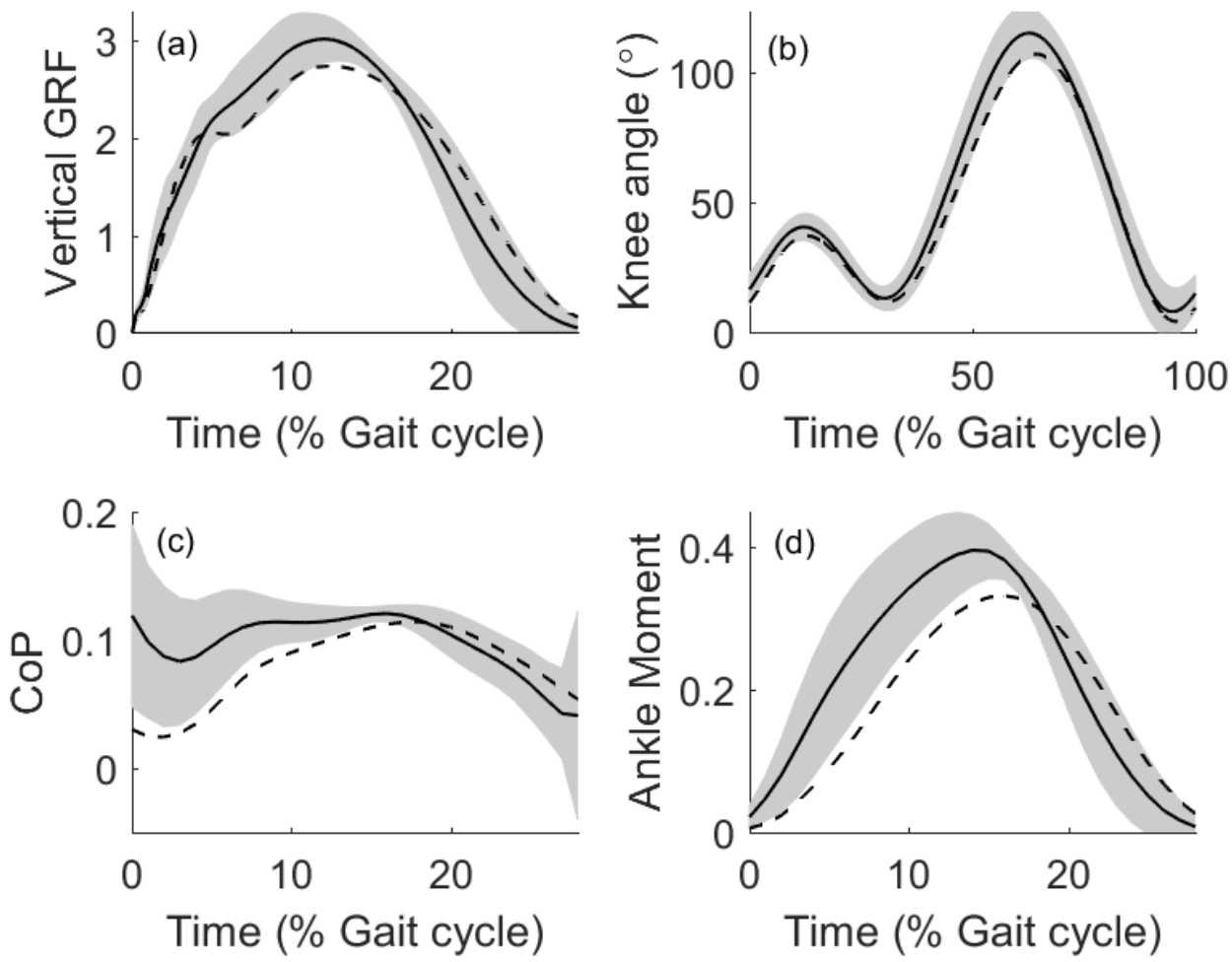

Figure 1: (a) Vertical Ground Reaction Force (GRF), (b) Knee flexion angle, (c) Centre of Pressure (CoP) in the AP direction expressed relative to the ankle joint centre and (d) Ankle plantar flexor moment. All data are shown for speed $2\left(3.9 \mathrm{~ms}^{-1}\right)$ for the high-performance (solid line) and the recreational runners (dashed line), with the shaded area representing the SD of the high-performance group. Note that data are presented in dimensionless form with GRF normalised to body weight $\left(m_{0} g\right)$, CoP normalised to leg length $\left(l_{0}\right)$ and moments normalised to $m_{0} g l_{0}$. 
Table 1

\begin{tabular}{|c|c|c|c|}
\hline Gender & Elite & Recreational & $\begin{array}{c}\text { P-val for group } \\
\text { comparison }\end{array}$ \\
\hline $\begin{array}{c}\text { Mean }(S D) \\
\text { Age }\end{array}$ & $29(3)$ years & $27(4)$ years & 0.12 \\
\hline $\begin{array}{c}\text { Mean }(S D) \\
\text { Weight }\end{array}$ & $64(10) \mathrm{Kg}$ & $62(9) \mathrm{Kg}$ & 0.6 \\
\hline $\begin{array}{c}\text { Mean }(S D) \\
\text { Height }\end{array}$ & $1.75(10) \mathrm{m}$ & $1.76(9) \mathrm{m}$ & 0.93 \\
\hline $\begin{array}{c}\text { Mean }(S D) \\
\text { 10 Km PB } \\
\text { time }\end{array}$ & $32(2) \mathrm{mins}$ & $43(3) \mathrm{mins}$ & $<0.001$ \\
\hline $\begin{array}{c}\text { Range } 10 \mathrm{Km} \\
\text { PB time }\end{array}$ & $30-35 \mathrm{mins}$ & $40-47 \mathrm{mins}$ & - \\
\hline $\begin{array}{c}\text { Weekly } \\
\text { mileage }\end{array}$ & $54(13) \mathrm{miles}$ & $24(7) \mathrm{miles}$ & $<0.001$ \\
\hline
\end{tabular}

Table 1: Demographic, training and performance characteristics for the highperformance and recreational group. 
Table 2

\begin{tabular}{|c|c|c|c|c|c|c|}
\hline & $\begin{array}{c}\text { HP mean } \\
\text { (SD) across } \\
\text { all 4 speeds }\end{array}$ & $\begin{array}{c}\text { Recr. mean } \\
\text { (SD) across } \\
\text { all 4 speeds }\end{array}$ & $\begin{array}{c}\text { Effect of } \\
\text { group }(\mathrm{p}- \\
\text { val) }\end{array}$ & $\begin{array}{c}\text { Effect } \\
\text { size for } \\
\text { group }\end{array}$ & $\begin{array}{c}\text { Effect of } \\
\text { speed } \\
\text { (p-val) }\end{array}$ & $\begin{array}{c}\text { Group } \\
\text { Interaction } \\
\text { (p-val) }\end{array}$ \\
\hline $\begin{array}{c}\text { Peak Ankle } \\
\text { plantarflexion } \\
\text { moment }\end{array}$ & $0.41(0.04)$ & $0.33(0.03)$ & $<\mathbf{0 . 0 0 1}$ & $\mathbf{2 . 2 3}$ & $<\mathbf{0 . 0 0 1}$ & 0.02 \\
\hline $\begin{array}{c}\text { CoP at } \\
\text { midstance }\end{array}$ & $0.13(0.01)$ & $0.11(0.01)$ & $<\mathbf{0 . 0 0 1}$ & $\mathbf{1 . 6 3}$ & $<0.047$ & 0.01 \\
\hline $\begin{array}{c}\text { Shank } \\
\text { inclination at } \\
\text { initial contact }\end{array}$ & $3.1(2.9)^{\circ}$ & $7.5(2.8)^{\circ}$ & $<\mathbf{0 . 0 0 1}$ & $\mathbf{1 . 5 3}$ & $<\mathbf{0 . 0 0 1}$ & 0.92 \\
\hline $\begin{array}{c}\text { Foot strike } \\
\text { index (\% foot } \\
\text { length) }\end{array}$ & $56(18) \%$ & $30(25) \%$ & $\mathbf{0 . 0 0 5}$ & $\mathbf{1 . 1 7}$ & $<\mathbf{0 . 0 0 1}$ & 0.07 \\
\hline $\begin{array}{c}\text { Vertical } \\
\text { impulse }\end{array}$ & $0.49(0.05)$ & $0.44(0.05)$ & $\mathbf{0 . 0 0 7}$ & $\mathbf{1 . 1}$ & $<\mathbf{0 . 0 0 1}$ & 0.76 \\
\hline $\begin{array}{c}\text { Vertical } \\
\text { velocity of } \\
\text { CoM at toe- } \\
\text { off }\end{array}$ & $0.24(0.02)$ & $0.21(0.02)$ & $\mathbf{0 . 0 1}$ & $\mathbf{1 . 0 5}$ & $<\mathbf{0 . 0 0 1}$ & 0.9 \\
\hline $\begin{array}{c}\text { AJC-CoM at } \\
\text { initial contact }\end{array}$ & $-0.20(0.03)$ & $-0.24(0.04)$ & $\mathbf{0 . 0 1}$ & $\mathbf{1 . 0 5}$ & $<\mathbf{0 . 0 0 1}$ & 0.83 \\
\hline $\begin{array}{c}\text { Flight time } \\
\text { at initial } \\
\text { contact }\end{array}$ & $18.9(5.7)^{\circ}$ & $14.2(3.9)^{\circ}$ & 0.02 & 0.94 & $<\mathbf{0 . 0 0 1}$ & 0.78 \\
\hline $\begin{array}{c}\text { Knee flexion } \\
\text { (0.06) }\end{array}$ & $0.45(0.05)$ & $\mathbf{0 . 0 2}$ & $\mathbf{0 . 9 2}$ & $<\mathbf{0 . 0 0 1}$ & 0.52 \\
\hline
\end{tabular}

Table 2: Two-way ANOVA analysis for the primary biomechanical variables. Note that CoM refers to Centre of Mass, AJC-CoM refers to distance from the Ankle Joint Centre to the Centre of Mass and CoP to the Centre of Pressure relative to the ankle joint centre, in the anterior-posterior direction. The table reports $\mathrm{p}$-values for the effect of group (High-Performance (HP) vs Recreational), the effect size (Cohen's d) for group, the effect of speed and the group/speed interaction. The variables are presented in rank order according to the p-value for the effect of group and significant differences (Bonferroni-Holm method used to adjust the critical alpha of 0.05) highlighted in bold. Note that all data are presented in dimensionless form 
Table 3

\begin{tabular}{|c|c|c|c|c|c|c|}
\hline & $\begin{array}{l}\text { HP mean } \\
\quad(\mathrm{SD}) \\
\text { across all } \\
4 \text { speeds }\end{array}$ & $\begin{array}{l}\text { Recr. mean } \\
\text { (SD) across } \\
\text { all } 4 \text { speeds }\end{array}$ & $\begin{array}{l}\text { Effect of } \\
\text { group }\end{array}$ & $\begin{array}{l}\text { Effect size } \\
\text { for group }\end{array}$ & $\begin{array}{l}\text { Effect of } \\
\text { speed }\end{array}$ & $\begin{array}{c}\text { Group } \\
\text { /Speed } \\
\text { Interaction } \\
\text { (p-val) }\end{array}$ \\
\hline Peak vGRF & $\begin{array}{c}2.96 \\
(0.18)\end{array}$ & $2.71(0.22)$ & 0.003 & 1.25 & $<0.001$ & 0.006 \\
\hline $\begin{array}{c}\text { Ankle } \\
\text { plantarflexion } \\
\text { at initial } \\
\text { contact }\end{array}$ & $-1.9(7.3)^{\circ}$ & $-6.3(8.7)^{\circ}$ & 0.16 & 0.55 & 0.94 & 0.22 \\
\hline $\begin{array}{c}\text { Stride } \\
\text { Frequency }\end{array}$ & $26.4(1.3)$ & $27.1(1.8)$ & 0.24 & 0.45 & $<0.001$ & 0.18 \\
\hline Contact time & $\begin{array}{c}0.65 \\
(0.03)\end{array}$ & $0.67(0.06)$ & 0.25 & 0.44 & $<0.001$ & 0.95 \\
\hline Stride length & $\begin{array}{c}3.41 \\
(0.22) \\
\end{array}$ & $3.31(0.27)$ & 0.28 & 0.42 & $<0.001$ & 0.2 \\
\hline $\begin{array}{l}\text { Peak Hip } \\
\text { extensor } \\
\text { moment }\end{array}$ & $\begin{array}{c}0.27 \\
(0.04)\end{array}$ & $0.28(0.04)$ & 0.46 & 0.28 & $<0.001$ & 0.04 \\
\hline $\begin{array}{l}\text { Hip flexion at } \\
\text { initial contact }\end{array}$ & $\begin{array}{l}25.6 \\
(5.9)^{\circ}\end{array}$ & $26.7(6.1)^{\circ}$ & 0.62 & 0.19 & $<0.001$ & 0.86 \\
\hline $\begin{array}{c}\text { Peak Knee } \\
\text { extensor } \\
\text { moment }\end{array}$ & $\begin{array}{c}0.28 \\
(0.04)\end{array}$ & $0.28(0.05)$ & 0.99 & 0 & 0.007 & 0.02 \\
\hline
\end{tabular}

Table 3: Two-way ANOVA analysis for the secondary biomechanical variables.

Note that vGRF refers to vertical Ground Reaction Force. The table reports p-values for the effect of group (High-Performance (HP) vs Recreational), the effect size (Cohen's d) for group, the effect of speed and the group/speed interaction. The variables are presented in rank order according to the $\mathrm{p}$-value for the effect of group and significant differences (Bonferroni-Holm method used to adjust the critical alpha of 0.05) highlighted in bold. Note that all data are presented in dimensionless form. 